\title{
LA GOBERNACIÓN GENERAL EN ARAGÓN DURANTE LA BAJA EDAD MEDIA
}

\author{
Esteban SARASA SÁNCHEZ \\ Universidad de Zaragoza
}

La Gobernación General en el reino de Aragón durante los últimos siglos medievales formó parte del conjunto institucional del que se sirvió la monarquía para controlar y gobernar dicho territorio. Los ordenamientos forales contemplaron la condición social de quienes ocuparon el cargo de gobernador entre los miembros del segundo brazo estamental de la nobleza: el de los caballeros. Cargo que, como el de Justicia, fue de nombramiento real, vitalicio aunque revocable y con atribuciones añadidas a las propias en situaciones de emergencia: como la organización de la defensa territorial o la suplencia de la autoridad real en épocas de interregno; tal y como sucedió con las guerras con Castilla o tras la muerte del rey Martín el Humano en 1410 sin sucesión directa y hasta la designación de Fernando de Trastámara en el Compromiso de Caspe'.

Jurídicamente, la Gobernación en Aragón se identifica con el «regente el oficio de la gobernación general en el reino de Aragón", denominándose asimismo gerens vices o portant vezes del gobernador general, a quien representaba; regulándose su situación y competencias a partir de $1348^{2}$.

1 Una aproximación al tema puede verse en Gobernador (Historia del Derecho), en Gran Enciclopedia Aragonesa, tomo VI, por J. LALINDE ABADÍA; y más extensamente, del mismo autor, «La Gobernación General en el reino de Aragón», en su libro sobre La Gobernación General en la Corona de Aragón, pp. 265-299, Zaragoza, 1963.

2 Año de celebración de unas importantes Cortes en Zaragoza cuando Pedro el Ceremonioso tuvo que hacer frente a la facción unionista, derrotándola en el verano de dicho año y convocando una asamblea de la que salieron abundantes acuerdos trasladados a los fueros de Aragón (Fueros, observancias y actos de corte del reino de Aragón, por Pascual SAVALL Y DRONDA y Santiago PENEN $Y$ DEVESA, Zaragoza 1866. Hay una edición facsimil por el Justicia de Aragón, Zaragoza 1990). 
Desde el punto de vista del derecho se trataba, no obstante, de un oficio ordinario, pues, a diferencia del virrey, no procede del rey sino de la ley, y, además perpetuo, siendo su jurisdicción para todo el reino, aunque no de primer orden porque de él se puede apelar, mientras que del gobernador general de la corona sólo se puede suplicar $^{3}$.

En Aragón se encuentra, además, desplazándose continuamente por todo el territorio para administrar justicia, mantener el orden y actuar en ocasiones excepcionales. $Y$ aun dependiendo orgánicamente del correspondiente superior, su intervención atendía directamente a los propósitos regios en el realengo y sin poder ejercer, en cambio, su jurisdicción en los señoríos; si bien se implicó a veces en las treguas de los ricoshombres y caballeros. Siempre con el compromiso de preservar los fueros, cuyo cumplimiento debía jurar ante el Justicia, junto con privilegios, libertades, usos y costumbres vigentes ${ }^{4}$.

Desde las Cortes de Zaragoza de 1348, se fueron fijando las normas y competencias que iban a regir el oficio de la gobernación, pero también sus limitaciones y dependencias:

«Idcirco nos Rex praedictus de voluntate, assensu omnium Praelatorum, Religiosorum, Nobilium, Mesnadariorum, Militum, Procuratorum civitatum, villarum et aliorum locorum totius Regni Aragonum, qui hanc Curiam convenerunt.

Statuimus et ordinamus in perpetuum, quod deinceps officium Gubernationis, seu Procurationis generalis, regatur et regi debeat per Militem naturalem et domiciliatum in Aragonia, qui utatur, debeat et habeat uti dicta officio: et habeat exercicium iurisdictionis civilis et criminalis eiusdem.

Sic quod Gubernator seu Procurator generalis dicti Regni dicto regimine et exercicio iurisdictionis civilis et criminalis non se intromittat nec se intromittere possit in futurum»

Condiciones que se acuerdan en un momento de especial alteración, debido a la guerra de la Unión que desde 1347 había conmocionado y enfrentado a los aragoneses $^{6}$, siendo por entonces gobernador de Aragón, Miguel de Gurrea ${ }^{7}$. Antes del cual

3 J. LALINDE ABADÍA, «La Gobernación General en el reino de Aragón», obra citada.

4 Algunos caballeros que ocuparon el cargo, por su condición de señores se vieron implicados incluso en disputas personales con otros señores por cuestiones familiares o de señoríos, como sucedió, por ejemplo en la época de Fernando Il el Católico (José Ángel SESMA MUÑOZ, La Diputación del reino de Aragón en la época de Fernando II, Zaragoza 1977, pp. 189, 272, 296, 312, 333, 335, $353,466,467$ y 468.

5 Fueros, observancias y actos de corte del reino de Aragón, obra citada, p. 33 y 34.

6 E. SARASA SÁNCHEZ, «El enfrentamiento de pedro el Ceremonioso con la aristocracia aragonesa: la guerra con la Unión y sus consecuencias» (en Pere el Ceremoniós i la seva època, Barcelona 1989, pp. 35-45).

7 J. ZURITA, Anales de la Corona de Aragón, ed. A. Canellas López, Zaragoza 1972 y ss. Libro VIII, capítulo VIII. 
apenas se menciona en la documentación algún nombre adscrito a dicho oficio y en circunstancias muy especiales: por ejemplo cuando en 1213, y por la minoría de Jaime I, aparecen los nombres de Pedro de Ahones para gobernar las ciudades y villas desde el Ebro hasta el Pirineo y de Pedro Fernández de Azagra para la frontera con Castilla y con los musulmanes valencianos ${ }^{8}$; o cuando en 1308 , el proceso desatado contra los templarios con Jaime II, puso al frente de algunas operaciones de asedio a los reductos del Temple a don Artal de Luna, como lugarteniente del "gobernador del reino", siendo éste el general de la Corona y el de Luna su delegado en el territorio aragonés ${ }^{9}$. Así como también el mismo Artal aparece como gobernador de Aragón en 1309 como servidor del rey, siendo:

«muy acompañado de caballeros, sus vasallos, y con mucha gente de caballo y de pie, en mayor número que otro ninguno de los ricos hombres que fueron a esta jornada' ${ }^{10}$.

quedando manifiesta la condición de ricohombre del mencionado con tal responsabilidad y no la de caballero que se fijaría definitivamente y según se ha visto en 1348; sin que anteriormente quedase clara la naturaleza del oficio de la gobernación que se establece en dicha fecha y por acuerdo de Cortes.

A partir de 1348, por tanto, la concreción sobre quienes aparecen documentados al frente de la institución objeto de estudio es mayor, como el caso de Miguel de Gurrea que se le nombra, al menos, entre 1352 y 1354 y actuando en los preparativos reales contra el infante Fernando, en las paces con Castilla y luego, incluso, en los apercibimientos contra dicho reino vecino"1.

Precisamente, con motivo de la guerra castellano-aragonsea de los dos Pedros, entre 1356 y 1369, y luego del aragonés con Enrique II hasta 1375, las intervenciones de los gobernadores de Aragón cobraron y adquirieron una actualidad permanente, tanto en las treguas como ante los episodios bélicos que hicieron peligrar la integridad territorial aragonesa. De hecho, durante todo este tiempo el gobernador por excelencia fue Garci López de Sesé ${ }^{12}$, quien colaboró con el Justicia y los jurados zaragozanos en la estrategia defensiva de la capital del reino que se vio amenazada por los castellanos ${ }^{13}$.

8 Ibídem, Libro II, capítulo LXVI.

9 Ibídem, Libro $V$, capítulo LXXIII.

10 Ibídem, Libro V, capítulo LXXX.

11 Ibídem, Libro VIII, capítulos XLVII, XLIX y LVI.

12 Al menos entre 1368 y 1373 (Ibídem, Libro X, capítulos III, V y XVI).

13 Un familiar suyo, estando de Justicia de Aragón, Juan López de Sesé, se había responsabilizado en 1357 de dicha misión (E. SARASA SÁNCHEZ, "Onomástica zaragozana del siglo XIV", en La ciudad hispánica durante los siglos XIII al XV, tomo II, Madrid 1985, pp. 1.201-1.214). 
Años en los cuales los gobernadores aparecen mencionados en actas de procesos de Cortes, interviniendo en el brazo o estamento de los caballeros ${ }^{14}$, si bien, en este caso al menos, sin una preeminencia, actuación o representación especial; como sí la tuvo, en cambio, el Justicia de Aragón, prorrogando las sesiones en nombre del rey y en su ausencia ${ }^{15}$.

Posteriormente, en el último cuarto del siglo XIV y primeros años del XV, hasta la muerte del rey Martín el Humano, Jordán Pérez de Urries y Gil Ruiz de Lihori se sucedieron en el cargo ${ }^{16}$; abriéndose a continuación un período especialmente significativo para el oficio, ya que durante el interregno y hasta el Compromiso de Caspe de 1412, el gobernador de Aragón y el Justicia asumieron la representación de dicho reino y se responsabilizaron de mantener el orden y reconducir la orfandad política hacia una salida pacífica y negociada, dirigiendo, incluso, las operaciones contra los conspiradores que buscaban aprovechar la ocasión para sus fines. Responsabilidad que el gobernador siguió teniendo en buena parte cuando, elegido Fernando de Antequera o de Trastámara, la causa del aspirante Jaime de Urgel fue defendida con las armas por Antón de Luna en algunas de las fortalezas pirenaicas ${ }^{17}$.

A lo largo del siglo $\mathrm{XV}$, los fueros recogieron los ordenamientos que se aprobaron en Cortes y concretaron, aún más, la situación del «regente el oficio de la gobernación». Así, en 1436, y estando el infante Juan de Aragón, hermano de Alfonso V, al que sucedería, y entonces rey consorte de Navarra, se ampliaba lo dispuesto a los oficiales de la curia o corte del gobernador:

«El regient el officio de la Governación del Regno de Aragón, es tenido de jurar en poder del señor Rey, de servar Fueros, usos, costumbres, privilegios e libertades del Regno de Aragón en la forma e manera en el Fuero contenidas. Y como las gentes del dito Regno a vegadas se seguían inconvenientes, por quanto no sabían el dito Regient el oficio de la Governación, si havía fecho el dito jurament o no. Por tanto de voluntad de la dita Corte statuimos y ordenamos quel dito Regient el oficio de la Governación, antes que use y pueda usar del dito oficio, sía tenido presentarse devant el lusticia de Aragón o de su Lugartenient e a aquel demostrar e fazer fe de la potestat

14 Cortes del reino de Aragón (1357-1451). Extractos y fragmentos de procesos desaparecidos, por A. SESMA MUÑOZ y E. SARASA SÁNCHEZ, Valencia 1976.

15 Cortes de Cariñena de 1357: «El día siguiente sábado, estando aiuntada la Corte y el Justicia de Aragón y procurador real, estando ausente el senyor rey, dicho Justicia de Aragón, que como por otros negocios graves del reyno, en senyor rey no huviesse podido venir aquel día a Cortes, por tanto, que dicho Justicia, por mandamiento de dicho senyor rey, que segín dixo le havía sido hecho cara a cara, continuava las Cortes para el día lunes siguiente» (Cortes del reino de Aragón, obra citada, $p$. 28). El gobernador en esas fechas era Jordán Pérez de Urríes (Ibídem, p. 23 y ss.).

$16 \mathrm{~J}$. ZURITA, Anales de la Corona de Aragón, obra citada, Libro X, capítulos XXVIII, LIX, LXV, $\mathrm{LXXIX}$ y XCI.

17 E. SARASA SÁNCHEZ, Aragón y el Compromiso de Caspe, Zaragoza 1981, y Aragón en el reinado de Fernando I (1412-1416), Zaragoza 1986. 
y de la comissión: la qual ha del dito su oficio y la carta pública por la cual paresce como él ha jurado en poder del señor Rey o de su Lugartenient, en el caso do por Fuero lo puede fazer en la forma y manera por Fuero statuydas: las quales potestat, comissión y carta pública de la jura del dito Regient se hayan a registrar e insertar en el registro del dito lusticia. Y que el dito Regient el oficio de la Governación, no pueda haver comissión pora fer enquestas contra los oficiales o Notarios del dito Regno. Y que el Assesor del dito Regient el oficio de la Governación sía tenido de jurar en poder del señor Rey o del Regient el oficio de la Governación, que en las cosas que pertenescen a su oficio, servará Fueros, Privilegios, libertades, usos e costumbres del Regno de Aragón. E si contra fará, encorra en las penas statuydas por Fuero contra los oficiales, delinquientes en su oficio. Y quel Notario del dito Regient, sía tenido de jurar de escrivir y escriva en los actos que se farán por el dito Regient de consello del dito Assessor, como se fan de consello del dito Assessor. Queremos empero que por el present Fuero no sía prejudicado a la acusación, que antes de la edición del present Fuero se podía fazer contra el Regient el oficio de la Governación contra Fuero en su oficio delinquient ${ }^{18}$.

Añadiéndose al respecto el carácter ordinario del oficio, la obligación de hacer justicia y dar razón de sus actuaciones, pues, ya anteriormente, en las Cortes de Teruel de 1428 se había rechazado la injerencia de otros oficios garantes del orden y perseguidores del delito, como los sobrejunteros, en el cumplimiento del oficio por parte de los gobernadores ${ }^{19}$.

De la misma forma que en los fueros de 1436 ya mencionados se consideraba que el gobernador no debía entrar en causas familiares ni de parentesco, así como que tan sólo pudiera tener un alguacil20.

Finalmente, ya reinando plenamente Juan II, en las Cortes de Calatayud de 1461, se estableció que:

«De voluntad de la Cort statuímos que sentencias interlocutorias o difinitivas $u$ otras provisiones o letras del dito Regient el oficio de la Governación en causas o feytos civiles o criminales de la edición del present Fuero adelant, no hayan effecto alguno, ni se puedan executar, ni se deban obtemperar, sino que sían feytas de e con consello del Assessor ordinario y general del dito Regient y natural y domiciliado en e del dito Regno, e jurista o sustituydo por el dito Assessor con que sía natural y domiciliado en e del dito Regno e jurista: de los defectos, delictos y culpas del qual principalment el dito Assessor ordinario sía tenido o que sían feytas por el dito Assessor

18 Fueros, observancias y actos de corte del reino de Aragón, obra citada, p. 34.

19 Ibídem, p. 37.

20 Ibídem, Cortes de Alcañiz. 
en su caso o por el dito substituydo en el suyo, residient el dito Regient en la ciudad, villa o lugar do se farán: de lo qual haya de constar por el processo y actos de las ditas sentencias y provisiones, el qual Assessor en su caso, substituydo en el suyo, antes que usen e usar puedan del dito officio, sían tenidos de jurar ultra las cosas otras que por Fuero son tenidos jurar y prestar homenage de manos y de boca que durant el dito oficio no advocaran en Cort alguna, ni recibiran directamente o indirecta pensión, cavallería o sobornación alguna.

Queremos empero quel dito Regient, no obstant lo sobredito, pueda por si fazer y mandar fazer provisiones de apellidos, emparas y recomendaciones de personas, citaciones, emparas de bienes, do quiere que le pertenez$\mathrm{ca}$, capciones de personas en fragancia de crimen, processo de notorio (excepto la sentencia y executoria de aquella) cognición de causas civiles, menores de cient sueldos: y aun cognición de causas civiles de voluntad de partes que no escedan quantía de mil sueldos y seguramentos.

$E$ no res menos, statuymos y ordenamos que si los Diputados del Regno de Aragón no faran las cosas que son tenidas fazer segund los Fueros de la present Cort y los Fueros feytos en la Cort de Maella por la Reyna doña María, de buena memoria, y en la Cort celebrada por ella mesma en la ciudad de Çaragoça, que puedan y hayan a seyer acusados delant el lusticia de Aragón, por la part de qui será interés o por qualquiere Procurador de los quatro braços por la vía privilegiada, como oficiales delinquientes en sus oficios contra Fuero.

Empero los Diputados Ecclesiásticos no puedan seyer punidos sino en privación de oficios del Regno o ocupación de temporalidades proprias dellos y de sus beneficios mientre los tenran. Queremos empero que los ditos Ecclessiásticos puedan en las ditas causas comparescer por Procurador» ${ }^{21}$.

En las Cortes de Maella de 1423, celebradas bajo la presidencia de la reina doña María por ausencia de Alfonso el Magnánimo ${ }^{22}$, se había hecho un acto de corte por el que se consignaba que: «mosen Blasco Fernández de Heredia se havía intitulado governador, lo qual no podía ser sino regente el officio de la governación, porque governador era el infante don Joan, y assí por esto se pretendía nullidad en los actos hechos por el dito mosen Blasco. $Y$ habilitáronse ahora para que no se pudiessen impugnar por esta razón.

Este Blasco se llama mosen Joan, alias Blasco. Y desta habilitación hubo algunos que allí se nombran que protestaron. $Y$ la reyna, de voluntad de la Corte, reservó a algunos qualquiere nullidad e injusticia que les huviesse sido hecha, exceptado la dicha de haverse intitulado governador ${ }^{23}$.

21 Ibídem, p. 35.

22 Cortes del reino de Aragón, obra citada, pp. 87-103.

23 Ibídem, p. 100. 
Posteriormente, en las Cortes de Zaragoza de 1451 se menciona al caballero Juan de Moncayo como "regente el officio de la general governación" "24, especificándose que actúa también como "consejero del rey", junto con el Justicia de Aragón, ante quien se presenta en calidad de tal dicho gobernador ${ }^{25}$. $Y$ a quien se le responsabiliza como capitán de la recluta de un contingente de gentes de caballo y ballesteros para hacer frente a los castellanos ${ }^{26}$.

De esta manera, aparte de lo que los fueros del reino estipulaban al respecto sobre el desempeño del oficio de la gobernación, su carácter, competencias, atribuciones y restricciones, según los momentos y necesidades, el regente del oficio, por su especial consideración, recibía encomiendas excepcionales que iban desde lo militar a lo curial, como capitán de una tropa o como embajador. Sin detrimento de las cautelas que los propios fueros recogían para evitar la injerencia en asuntos impropios de su cargo o la intromisión en las ejecuciones de otros oficios.

Así pues, a lo largo del siglo XV, con los trastámaras, se fue perfilando el oficio de la gobernación, y los gobernadores adquirieron una mayor consideración y preeminencia, casi siempre junto con el Justicia Mayor, que en dicha centuria también adquirió una categoría superior a la que hasta entonces había obtenido.

A fines de la época medieval, cuando en 1472 se alteró todo el reino con motivo de los bandos feudales que enfrentaron a los Lunas y los Urrea, el entonces gobernador de Aragón, don Juan López de Gurrea y Torrellas, facilitó con su mediación una tregua entre los contendientes. Incluso la ciudad de Zaragoza entró en disensión, y como escribe Zurita: «se impuso a las partes la tregua foral de seis meses, conforme al fuero de los guerreantes; y fue aceptada y jurada por las partes, en lo cual puso gran diligencia don Juan López de Gurrea y Torrellas gobernador de Aragón „27. Al cual sucedió en 1479 Juan Fernández de Heredia, quien contemplo la llegada a sus nuevos reinos de Fernando II el Católico ${ }^{28}$.

A partir de entonces, la gobernación general iba a cambiar de rumbo dentro del contexto general que la nueva visión política del Estado y de la administración y gobierno, de la Corona de Aragón en particular y del estado nacional de los Reyes Católicos primero y de los Austrias después, reconducirían en la época moderna.

Hasta entonces, pues, y desde 1348 , se habían ido dando pasos adelante para confirmar una institución que en el reino de Aragón representó un papel primordial en el gobierno del territorio, la defensa del orden y la resolución de problemas surgidos entre la monarquía compartida por los diferentes estados de la Corona y los aragoneses; ocupando un lugar intermedio y por debajo del gobernador general. Sólo cuando en el siglo XVI fue decayendo el cargo superior, los fueros hablarán exclusivamente del "regente del oficio de la gobernación" en el reino, emancipándose de la depen-

24 Ibídem, pp. 143-198.

25 Ibídem, pp. 160-161.

26 Ibídem, pp. 179 y 182.

27 Anales de la Corona de Aragón, obra citada, Libro XVIII, capítulo XLV.

28 Ibídem, Libro XX, capítulo XXIX. 
dencia de la gobernación general pero supeditándose a la lugartenencia general y quedando a veces ensombrecido por la figura emblemática del Justicia Mayor que no existirá en otros reinos de la Corona ${ }^{29}$.

De hecho, desde las Cortes de Alcañiz de 1436, presididas por el infante de Aragón don Juan, por entonces rey consorte de Navarra y futuro Juan II en aquél, y lugarteniente de Aragón por su hermano Alfonso $\mathrm{V}$ el Magnánimo, se requería el juramento del regente de la gobernación ante el rey y el reino sobre la observancia de los fueros, usos, costumbres y privilegios; debiendo presentar ante el Justicia la «carta pública» que confirmase dicho juramento, dando dicha magistratura la fe correspondiente y quedando registrado el hecho en su corte ${ }^{30}$.

Finalmente, toda la doctrina elaborada y aforada sobre la gobernación general en Aragón a lo largo de la Edad Media y en el siglo XVI fue estudiada y sistematizada en 1592 por el jurista Bardaxí en su Tractatu de officio gubernationis, seu procurationis generalis Regni Aragonum, con el tratamiento de los siguientes temas: «De officio assesoris regentis officium Gubernationis Aragonum, De officio alguazirii regentis officium gubernator Regni Aragonum, De portario regentis officium gubernationis y Tractatus de officio gubernationis seu procurationis generalis Regni Aragonum in criminalibus's.

Con ello, dentro de la tradición jurídica aragonesa que desde la época medieval y, sobre todo, en la Edad Moderna iba a proporcionar ilustres plumas, la figura del regente de la gobernación en el reino cabeza de la Corona común, tuvo su especial relieve a través de lo que Bardaxí recogió de la trayectoria precedente y de lo que sentó doctrinalmente para su posteridad. De manera que, como colofón, a modo de muestra de la situación al final de la épcoa foral, el documento presentado a continuación y que publicó Lalinde Abadía en el apéndice de su libro sobre La Gobernación General en la Corona de Aragón, puede servir de referencia ${ }^{31}$ :

Acta de insolutundación otorgada por el lllustrisimo Señor Don Josseph de Urries y Marcilla Cavallero Mesnadero, Señor de Escoron y Canales, y de las Villas de Frescano, Fraella, Vicien y Albero en favor del Illustrisimo Señor Don Dionisio Ximenez de Urrea.

A.C.A. C. de A., leg. 34

Año 1689

In Dei nomine. Manifiesta sea a todos que yo Don Joseph de Urries y Marcilla Cavallero Mesnadero, Señor de Escoron y Canales y de las Villas de Frescano, Fraella, Urrien y Albero domiciliado en la ciudad de Zaragoza. Desde aora para siempre y quando llegase el casso de entrar a goçar el officio de Regente la General Gobernacion de este Reyno de que su Magestad (Dios le guarde) me a hecho merced para despues de los largos dias y vida natural del Illustrisimo Señor Don Pedro Geronimo de Urries

29 J. LALINDE ABADÍA, obra citada.

30 Ibídem.

31 Ibidem, pp. 530-534. 
Auguian y Navarra mi Padre y señor de grado y de mi cierta ciencia certificado de mi derecho y de mis herederos y sucesores con y por tenor y titulo de la presente escriptura publica de insolutundacion y consignacion para siempre firme y valedera, y en cosa alguna no revocadera asigno y consigno y Insolutundacion hago al Illustrisimo Señor Don Dionisio Ximenez de Urrea domiciliado en dicha Ciudad para durante su vida para Su Señoria y los suyos y para quienes querran y ordenaran en y sobre el salario de quatro mill libras jaquesas que como tal Regente el Officio la General Gobernacion de este Reyno y por dicha merced de su Magestad de goçar sobre las Generalidades de dicho y presente Reyno de Aragon y Recepta de la Vailia General del mismo Rey es a saver Dos mil libras jaquesas en cada un año de los que yo sirviese dicho officio, y durante la vida de dicho Illustrisimo Don Dionisio en esta manera, las mil quinientas quarenta y ocho libras y quince sueldos jaqueses en las dichas Generalidades del dicho Reyno de Aragon; y las otras quatrocientas cinquenta y una libras y cinco sueldos jaqueses restantes en la dicha Recepta de dicha Vaylia General de dicho Reyno cuya primera paga a de hazerme a dicho Illustrisimo Señor Don Dionisio desde el dia de dicho otorgante jure en el dicho officio de Regente la General Gobernacion en cada un año por las mismas personas a quien tocase la paga en los tercios y pagas, y de la forma y manera que a los que han servido dicho officio se han pagado y acostumbran pagar de tal manera que los dichos tercios y pagas de dicho officio han de ser con igualdad cobrando dicho Illustrisimo Señor D. Dionisio o su Procurador o havientes derecho la mitad de dicho tercio o paga y yo y los mios la otra mitad sin que en esta cobranza ni su Señoria ni yo podamos tener mejora alguna en tiempo ni en paga porque mi voluntad es que dicho Illustrisimo Señor D. Dionisio, o sus havientes derecho cobren la dicha cantidad si quiere mitad de dicha renta que por la presente le consigno en cada un año de los que yo tuviere dicho officio y durante la vida de dicho Illustrisimo señor D. Dionisio, sin retardacion alguna, y con todo effecto sin mas recados y con sola obtencion de la presente consignacion y para la cobranza de dichas Dos mil libras jaquesas en cada un año de los que yo sirviese dicho officio y durante la vida de dicho Illustrisimo Señor D. Dionisio tan solamente en los tercios y pagas sobre dichas y por mayor firmeza de lo sobredicho juntamente con la presente hago cesion a su Señoria y le doy poder en causa propia con vastante forma y la que de derecho y fuero del dicho Reyno de Aragon o en otra manera se requiere y es necesario para cobrar las dichas Dos mil libras jaquesas en cada un año mientras yo tuviese dicho officio y le sirviese y durante la vida de dicho Illustrisimo Señor D. Dionisio y hazer de ellas a su arbitrio y voluntad como de bienes y cosa suya propia de las quales dichas Dos mil libras jaquesas en cada un año de los que yo tuviese dicho officio y durante la vida de dicho Illustrisimo Señor D. Dionisio le consigno en la forma sobredicha, y hago a su Señoria insolutundacion consignacion y cesion 
con todos y cada unos dichos Procesos instancias y acciones a mi pertenecientes e pertenecer podientes y revientes, en qualquiere manera para poder recivir y cobrar la dicha cantidad queriente y expresamente consintiente que dicho lllustrisimo Señor D. Dionisio en su caso y quien su señoria querra ordenara y mandara recivan y cobren dichas Dos mil libras jaquesas en cada un año de los que yo sirviere dicho officio y durante la vida de su Señoria con todos los dichos procesos instancias y acciones y para recivir, tener, poseher, dar, vender y empeñar aquellas y hazer de ellas a su voluntad tengo y me pertenezen segun que mas util y provechoso puede y deve ser dicho escrito y entendido a toda voluntad de dicho lllustrisimo Señor D. Dionisio y de los suyos a toda contrariedad mia y de los mios y de toda otra qualquier persona cesante intimante y requiriente por tenor de la presente la qual quiero haver y he en lugar de ipoteca al Receptor de dicha Vailia General del dicho Reyno de Aragon y al administrador o arrendador de las dichas Generalidades del mismo Reyno que respectivamente son y por tiempo seran, o a la persona o personas a quienes tocare la paga y solucion de dicho mi officio de Regente la General Gobernacion de dicho Reyno, paguen en cada un año de los que yo tuviese dicho officio y durante la vida de dicho Illustrisimo Señor D. Dionisio con effecto las dichas Dos mil libras jaquesas a dicho Illustrisimo Señor D. Dionisio, o, a quien su derecho huviese en la forma arriva dicha con esto doy a su Señoría todos mis derechos instancias y acciones Reales y personales utiles y directas mixtas tacitas y expresas ordinarias y extraordinarias, y otras qualesquiera con las quales pueda dicho Illustrisimo Señor D. Dionisio usar y exercer en juicio y fuera de el a su arbitrio y voluntad constituyendole señor verdadero como en cosa suya propia puede hazer y lo que yo mismo haria y hacer podria antes de la concesion de la presente. Personalmente prometo y me obligo a dicho Illustrisimo Señor D. Dionisio serle tenido y obligado a ebicción plenaria y leal defension de lo sobredicho que le doy y insolutundacion hago y consigo asi que si en algun tiempo le fuese puesto a dicho Illustrisimo Señor D. Dionisio o a los suyos pleyto o mala voz sobre las dichas dos mil libras jaquesas anuales y de la presente consignacion y en qualquiere parte de ellas, por qualesquiere persona 0 personas Cuerpos Colegios y Universidades de qualquiere estado grado preheminencia o condicion sean por hecho acto trato o contracto de mi dicho otorgante $o$ descendientes de el en qualquiere manera prometo y me obligo en tal caso sacar a paz al dicho Illustrisimo Señor D. Dionisio y a los suyos siguiendo dicho pleyto a mis costas hasta sentencia definitiva pasada en cosa juzgada de la qual no puede haver recurso apelacion o de nulidad, o puestos y dicho Illustrisimo Señor D. Dionisio y los suyos esten en posesion y tengan pacificamente en su poder las dichas Dos mil libras jaquesas en cada un año si quiere la mitad de dicha renta empero quiero y me plaze que quede en elección del dicho lllustrisimo Señor D. Dionisio el llevar y proseguir, por si mesmo los dichos pleytos y mala voz o el dejarlos a cargo mio, 
o de los que tuviesen mi derecho, remitiendo y relajandole por pacto especial toda necesidad de denunciar los dichos pleytos y mala Voz, y de apelar y la apelación proseguir. Y si sucediese al dicho lilustrisimo Señor D. Dionisio perder o menoscavar las dichas Dos mil libras en cada un año de los que yo tuviere y sirviese dicho officio y durante la vida de dicho lllustrisimo Señor D. Dionisio perder o menoscavar las dichas Dos mil libras jaquesas en cada un año de los que yo tuviese dicho officio y durante la vida del lliustrisimo Señor D. Dionisio o parte alguna de dicha cantidad por hecho acto, trato o contracto propio de mi dicho otorgante o descendiente de el en qualquiere manera prometo y me obligo, que le restituere dare y pagare otra tanta cantidad como perdiere y se le menoscavare de la cantidad y anua renta que por la presente le insolutundo y asigno y consigno y le pagare todas las cosas y daños que por razon de lo sobredicho huviese de los quales y de las quales quiero sea creydo por su asercion y palabra sin testigo juramento ni otra manera de prueba requerida y al cumplimiento de todo lo sobredicho obligo mi Persona y todos mis bienes así muebles como sitios donde quiere havidos y por haver de los quales los muebles quiero aqui haver y he por nombrados, y los sitios por confrontados y limitados, y los censales treudos creditos derechos Procesos infamias y acciones por calendados, y declarados con los nombres sobrenombres, y autoridades de los notarios que aquellos hayan testificado, por puestos y nombrados todo devidamente y segun fuero del presente Reyno de Aragon, la qual obligacion quiero sea especial y havida por tal y que surta el devido effecto y la especial ipoteca segun fuero de dicho y presente Reyno y en dicha manera surtir puede y deve y para mayor seguridad de lo sobredicho reconozco y confieso tener y poseer los dichos bienes de parte de arriva havidos por especialmente obligados NOMINE PRECARIO y constituto de dicho Illustrisimo Señor Don Dionisio de tal manera que la posesion civil y natural de mi dicho otorgante en los dichos bienes sea havida por propia de dicho lllustisimo Señor D. Dionisio, $y$ de sus havientes derecho y que con sola la presente escriptura sin otra liquidacion posesion ni provanza alguna por la razon sobredicha los dichos bienes sitios pueden ser aprehendidos y los muebles censales treudos y creditos inbentariados executados y emparados a mano y poder de qualquiere Juez y tribunal que elixir querran y que obtengan y ganen en su favor sentencia, o sentencia asi interlocutorias como difinitivas en qualquiere de los procesos de aprehension imbentario emparamiento y execucion asi en los articulos de lite pendente como en los de la tenuta firmas y propiedad asi en primera instancia como en grado de apelacion y en virtud de las dichas sentencias y de la de ellas puedan poseer, y usufructuar los dichos bienes hasta entera satisfaccion que haga de lo sobredicho, y con esto me obligo al tiempo de la execución, por la dicha raçon hacedera a dar y asignar, y que dare y asignare bienes mios prpios libres y quitos a cumplimiento de todas y cada unas cosas sobre otras y quiero que puedan ser sacados de 
qualquiere parte y lugar que fuesen hallados por privilegiado que sea, y que se executen y vendan a uso y costumbre de corte de Alfarda sin guardar solemnidad alguna, de fuero ni derecho la qual renuncio y tambien renuncio, qualesquiere escepciones difugios y defensiones de fuero derecho observancia uso y costumbre del presente Reyno a lo sobredicho repugnantes, y a mis propios Juezes ordinarios y locales y por dicha razón me someto a la jurisdiccion y conocimiento de qualesquiere Juezes y officiales asi eclesiasticos como seculares superiores e inferiores ante quien por la dicha raçon mas combenirme querran y prometo ante ellos y qualquiere de ellos hazer cumplimiento de derecho y de justicia, y quiero que pueda ser variado juicio de un juez a otro y de una instancia execucion y proceso a otro y otros a propias costas mias tantas vezes quantas quisieren y quiero que el juicio ante un Juez comenzado no empache al otro o otros, antes bien puedan todos concurrir en un mismo tiempo no obstante qualesquiere fuero ley 0 derecho a las sobredichas cosas repugnantes; y para mayor firmeza y seguridad de lo sobredicho yo dicho otorgante juro a Dios nuestro Señor sobre la Cruz, y quatro Santos Evangelios en poder del Notario Publico e infrascripto como Publica y autentica Persona la presente legitimamente estipulante y reciviente que cumplire y pagare realmente y con effecto al dicho Illustrisimo Señor D. Dionisio en caso que no cobrase la dicha cantidad de la presente consignacion en cada un año de los que yo fuese Regente el officio la General Gobernacion del presente Rey por hecho acto trato o contacto propio de mi dicho otorgante o descendientes de el en qualquiere manera juntamente con las costas como dicho es, y que por la dicha raçon no pleytease ni presentare firma solas penas del dercho. Hecho fue lo sobredicho en la Ciudad de Zaragoza del reyno de Aragon el dia treinta del mes de abril del año contado del Nascimiento de Nuestro Señor Jhesuchristo de Mil seiscientos ochenta y nuebe, siendo testigos Juan Salbador Martinez y Pedro Ximenez de Aragon domiciliado en dicha ciudad, esta firmado este acto en su Nota original según fuero deste reyno de Aragón.

Signo de mi Braulio de Villanueva Notario del Numero de la Ciudad de Çaragoza, del regno de Aragon. Que a lo sobredicho presente fui, Apruebo los trazos enmendados, donde se lehe, etc... 